\title{
Development of a cyclic voltammetry method for the detection of Clostridium novyi in black disease
}

\author{
L.L. Liu, D.N. Jiang, G.M. Xiang, C. Liu, J.C. Yu and X.Y. Pu \\ Department of Clinical Laboratory, Xinqiao Hospital, \\ Third Military Medical University, Chongqing, China \\ Corresponding author: X.Y. Pu \\ E-mail: xqyyjyk@aliyun.com
}

Genet. Mol. Res. 13 (1): 1724-1734 (2014)

Received June 10, 2013

Accepted October 27, 2013

Published January 14, 2014

DOI http://dx.doi.org/10.4238/2014.January.14.9

\begin{abstract}
Black disease is an acute disease of sheep and cattle. The pathogen is the obligate anaerobe, Clostridium novyi. Due to difficulties of anaerobic culturing in the country or disaster sites, a simple, rapid, and sensitive method is required. In this study, an electrochemical method, the cyclic voltammetry method, basing on loop-mediated isothermal amplification (LAMP), electrochemical ion bonding (positive dye, methylene blue), was introduced. DNA extracted from C. novyi specimens was amplified through the LAMP reaction. Then the products combined were with methylene blue, which lead to a reduction in the oxidation peak current (ipA) and the reduction peak current (ipC) of the cyclic voltammetry. The changes of $\mathrm{ipA} / \mathrm{ipC}$ were real-time measured by special designed electrode, so the DNA was quantitatively detected. The results displayed that this electrochemical detection of $C$. novyi could be completed in $1-2 \mathrm{~h}$ with the lowest bacterial concentration of $10^{2}$ colony forming units $/ \mathrm{mL}$, and high accuracy (96.5\%), sensitivity (96\%), and specificity (97\%) compared to polymerase chain reation. The cyclic voltammetry method was a simple and fast method, with high sensitivity and high specificity,
\end{abstract}


and has great potential to be a usable molecular tool for fast diagnosis of Black disease.

Key words: Real-time; Cyclic voltammetry; Clostridium novyi; Black disease

\section{INTRODUCTION}

Black disease is an acute, highly fatal disease of sheep and cattle, which is caused by Clostridium novyi. C. novyi survives in the environment as a durable spore (Aronson and Fitz-James, 1976). Wound infection by C. novyi and many other Clostridium species causes gas gangrene (Hatheway, 1990). The onset of disease and death is usually so rapid that treatment is rarely successful or worthwhile (Parsonson, 2007). Evidence indicates that outbreaks of black disease are at least partially responsible for the massive coral mortality at the northern reef, although human activities and heat-related coral bleaching cannot be discounted as minor causes for this coral decline (Shi et al., 2012). Thus, early diagnosis and prompt treatment are important in preventing disfiguring complications.

C. novyi is a Gram-positive, endospore-forming, obligate anaerobic bacteria. It comes in 3 types, labeled A, B, and a non-pathogenic type, C. A combination of $16 \mathrm{~S}$ rDNA and fliC gene sequencing of bacterial DNA isolated from spoiled meat samples revealed the unique presence of $C$. novyi type B. Although this bacterium has been implicated in clinical necrotic hepatitis in cattle, the cases described here are the first implicating C. novyi type B as a cause of bovine meat spoilage (Eeckhaut et al., 2012). The existing tools for diagnosis include microscopy, antigen/enzyme detection kits, and molecular tools. Microscopic diagnosis is the old method, remaining the only feasible options in many endemic countries. Anaerobic cultivation is currently used as the "gold standard". It was commonly applied in phylogenetic analysis of the 16S RNA gene sequence of C. butyricum (Belokopytov et al., 2012). However, it requires relatively high-standard laboratory facilities and is a time-consuming process (Brazier et al., 2002). Badenoch et al. (2007) pointed out that anaerobic bacteria are rarely implicated in infections. In his laboratory, only 3 of a series of 432 bacterial isolates from the cornea were anaerobes. This fraction is not unusual. The real reason was likely due to lack of anaerobic culture or failure to culture due to errors in the collection, transport, detection, and other steps. Therefore, a simple, rapid, and accurate detection method of anaerobic bacteria is required.

Recently, polymerase chain reaction (PCR) has become the common method of DNA detection. On the basis of PCR, scientists have developed a series of technologies, such as quantitative real-time PCR (An et al., 2012), multiplex PCR (Traverso et al., 2006), chip PCR (Cooney et al., 2012), microfluidic PCR (Yue et al., 2012), and isothermal PCR (Paris et al., 2011). Loop-mediated isothermal amplification (LAMP) was invented by Dr. Notomi in 2000 (Notomi et al., 2000), and is characterized by its rapidity, high specificity, and high sensitivity. It uses the bst DNA polymerase in a constant temperature $\left(65^{\circ} \mathrm{C}\right)$ and completes DNA amplification in 20-60 min. In recent years, LAMP has contributed to progress in detections of viruses (Wang et al., 2012), bacteria (Sowmya et al., 2012), parasites (Abdul-Ghani et al., 2012), food safeties (Zhang et al., 2012), and animal embryo sex identifications (Nogami et al., 2008). LAMP is relatively simple and could amplify DNA with high specificity. With the development of gene chips, more attentions has been paid to PCR or LAMP reactions on mi- 
crofluidic gene chips. Due to the small volume, the electrochemical detection method is more suitable for the detection of DNA on the gene chip (Chang et al., 2005).

In this paper, we propose an electrochemical method, the cyclic voltammetry method, based on LAMP, for the detection of C. novyi. First, the DNA of C. novyi extracted from specimens was amplified through the LAMP reaction. Then, the products were combined with positive dyes such as Methylene blue (Xu et al., 2012), leading to a reduction in the oxidation peak current (ipA) and reduction peak current (ipC) of the cyclic voltammetry. The changes of ipA/ $\mathrm{ipC}$ were real-time measured by a specially designed electrode, allowing the DNA to be quantitatively detected. Finally, the cyclic voltammetry method was compared with PCR, to test its accuracy, sensitivity, and specificity. Therefore, the goals of early diagnosis and prompt treatment of Black disease could be achieved. The scheme of the experiment is shown in Figure 1.

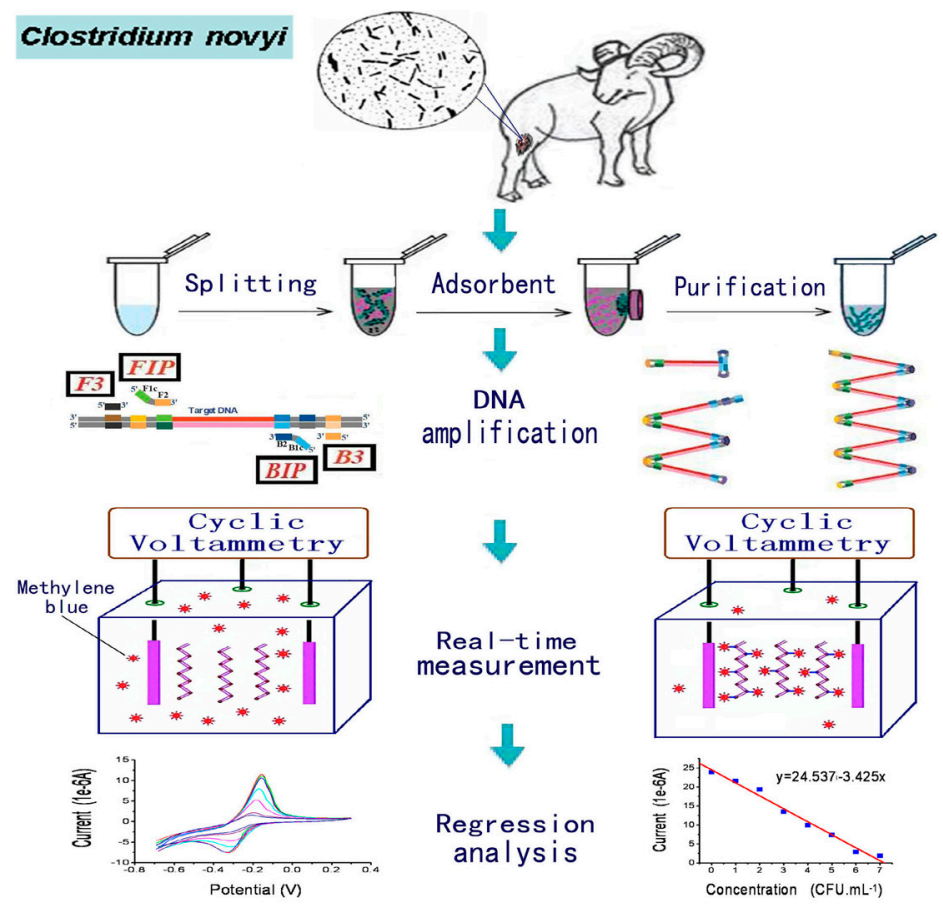

Figure 1. Scheme of Clostridium novyi detection by the cyclic voltammetry method.

\section{MATERIAL AND METHODS}

\section{Reagents}

The LAMP reagents were purchased from Eiken Chemical (Japan). The DNA extraction reagents were provided by Tiangeng (China). The LAMP primers were designed by PrimerExplorer 4.0 online (Eiken, Japan), and the PCR primers were designed by PrimerPremier 5.0 (Premier; Canada). The methylene blue was obtained from Sigma-Aldrich (USA) and diluted to appropriate concentration prior to use. All other reagents were analytical grade. The anaerobic mediums contained, per liter: yeast extract, $10.5 \mathrm{~g}$; peptone, 
$12.5 \mathrm{~g}$; glucose, $5 \mathrm{~g}$; soluble starch, $1 \mathrm{~g}$; NaCl, $5 \mathrm{~g}$; sodium acetate, $3 \mathrm{~g}$; and cysteine $\mathrm{HCl}$, $0.6 \mathrm{~g}$, were made by Pangtong (China). All solutions were prepared using Millipore-Q water $(\geq 18 \mathrm{M} \Omega)$.

\section{Bacterial strains and growth conditions}

Three types standard strains of C. novyi (type A: ATCC 19402, type B: ATCC 25758, C: ATCC 27323), and 10 kinds of other bacteria standard strains which need to be differentiated: $C$. perfringens (ATCC 13124), C. difficile (ATCC 9689), C. tetani (ATCC 19406), C. histolyticum (ATCC 19401), C. septicum (ATCC 12464), Acinetobacter baumannii (ATCC 19606), Enterococcus faecalis (ATCC 14506), Escherichia coli (ATCC 25922), Staphylococcus aureus (ATCC 25923), Pseudomonas aeruginosa (ATCC 27853), were obtained from American Type Culture Collection (ATCC; USA), grown on the corresponding medium (Pangtong; China), 24$72 \mathrm{~h}$, and preserved in normal saline (NS) at $-20^{\circ} \mathrm{C}$ until detection.

\section{Animal model and ethical approval}

The samples used in this study were obtained from sheep Black diastase models. Five sheep (average 1 year old and $30 \mathrm{~kg}$ ) were obtained from the experimental animal center of Third Military Medical University [laboratory animal license: SYXK(YU)20070002]. The experiments were approved by the ethics committee of Xinqiao hospital. The sheep were judged to be healthy based on complete physical and microbiological examinations. Two wounds $(5 \mathrm{~cm}$ wide and $3 \mathrm{~cm}$ deep) were made in back legs and injected $2 \mathrm{~mL}$ C. novyi type B (ATCC 25758) in broth medium (10 $\mathrm{CFU} /$ $\mathrm{mL}$ ). The wounds were well bandaged after operation to create anaerobic conditions. The sheep were given normal feed for 1-5 days, and the performance of the wound was observed. The sheep infected successfully would have fever, local wound ulceration, skin blackening, gas gangrene, or be dead. Autopsy revealed hepatic necrosis and other symptoms. Blood, urine, wound exudates, liver tissue, and necrotic skin tissue were collected. One hundred specimens (20 different sites and types specimens from 5 sheep) were collected to detect C. novyi and preserved at $-20^{\circ} \mathrm{C}$.

\section{Primer design and synthesis}

The nucleotide sequences expressed specifically in C. novyi were retrieved from Genbank, National Center for Biotechnology Information (NCBI) as target genes. The LAMP primers were designed using PrimerExplorer 4.0 (Eiken) online. The primers were designed according to conserved regions. All primers were synthesized by Sangong (Shanghai, China). The primers were stored at $-20^{\circ} \mathrm{C}$ and were diluted in appropriate buffer prior to use.

\section{Optimization of the cyclic voltammetry measurement}

Conventional detection $(>1.0 \mathrm{~mL})$ was performed using SPE glassy carbon electrode 
61208110 (Metrohm, Spain). Small sample detection $(<1.0 \mathrm{~mL})$ was performed using platinum electrodes (designed and made by our laboratory). The platinum electrodes included a working electrode (platinum electrode), an opposing electrode (platinum electrode), and a reference electrode ( $\mathrm{Ag}-\mathrm{AgCl}$ electrode). The DNA amplifications were reacted in the thermobath ALB64 (Finepcr, Korea). The electrochemical detections were performed on the 910 PSTAT mini system (Dropsens, Spain). The DNA of $1.0 \mathrm{~mL}$ C. novyi type B $\left(1 \times 10^{5} \mathrm{CFU} / \mathrm{mL}\right)$ was extracted by using the bacteria DNA extraction kit. The DNA amplification was carried out in a specific reaction tube containing $2 \mu \mathrm{L}$ template DNA, $12.5 \mu \mathrm{L}$ reaction reagent, $1.0 \mu \mathrm{L}$ bst DNA polymerase, $4 \mu \mathrm{L}$ primer mixture (containing 4 primers: $10 \mu \mathrm{M} \mathrm{F} 3$ and B3, $40 \mu \mathrm{M}$ FIP, and BIP), $1 \mu \mathrm{L} 2.0 \mathrm{mg} / \mathrm{L}$ Methylene blue, and 4.5 $\mu \mathrm{L}$ double-distilled water. The mixture in the reaction tube was incubated isothermally at $65^{\circ} \mathrm{C}$ for $60 \mathrm{~min}$. The ipA/ipC of cyclic voltammetry was completed on the OriginPro 7.5 software (OriginLab; USA).

\section{Specificity analysis of the method}

Three types of $C$. novyi and 10 kinds of other bacteria were commonly found in infected wounds (C. perfringens, C. difficile, C. tetani, C. histolyticum, C. septicum, A. baumannii, E. faecalis, E. coli, S. aureus, and P. aeruginosa). They were cultured, counted, diluted to the same concentration $\left(10^{6} \mathrm{CFU} / \mathrm{mL}\right)$, DNA extracted, and $C$. novyi measured in the same way.

\section{Sensitivity and regression analysis of the method}

The C. novyi type B (ATCC 25758) were grown at $37^{\circ} \mathrm{C}$ for $24 \mathrm{~h}$ on Columbia blood agar plates (Pangtong; China). The counts were performed by plating $100 \mu \mathrm{L}$ dilutions in sterile phosphate buffer saline on plate and incubating for $24 \mathrm{~h}$ at $37^{\circ} \mathrm{C}$. Then, the average number of CFUs were counted. C. novyi solution was diluted into a serial of concentrations (from $1 \times 10^{\circ}$ to $1 \times 10^{6} \mathrm{CFU} / \mathrm{mL}$ ), DNA extracted, and C. novyi measured in the same way. The semi-logarithmic linear regression was analyzed by using the OriginPro 7.5 software.

\section{Comparative analysis with PCR}

The samples were divided into 2 parts. One part was identified by the cyclic voltammetry measurement, and the other part was amplified by PCR. The PCR assay, using $25 \mu \mathrm{L}$ multiplex-PCR mixtures, contained $2.0 \mu \mathrm{L}$ primers $\mathrm{F}$ and $\mathrm{B}$ (Table 1), 12.5 $\mu \mathrm{L} 2 \mathrm{X}$ Fast qPCR MasterMix (Eurogentec Deutschland GmBH; Germany), and $2.5 \mu \mathrm{L}$ template DNA. Thermal cycling conditions comprised a uracil-n-glycosylase (UNG) step at $50^{\circ} \mathrm{C}$ for $2 \mathrm{~min}$, hot start DNA polymerase activation at $95^{\circ} \mathrm{C}$ for $5 \mathrm{~min}, 40$ cycles of denaturation at $95^{\circ} \mathrm{C}$ for $3 \mathrm{~s}$, annealing at $64^{\circ} \mathrm{C}$ for $30 \mathrm{~s}$, and extension at $72^{\circ} \mathrm{C}$ for 10 s. The products were analyzed by electrophoresis on $2 \%$ agarose gels (Biowest, Spain) at $100 \mathrm{~V}$ for $50 \mathrm{~min}$, and visualized in a Kodak Gel Logic 212 PRO Imaging System (Eastman Kodak, USA). The results were compared with difference $\left(\chi^{2}\right.$ test), accuracy, sensitivity, and specificity. 


\section{RESULTS}

\section{Primer design of $C$. novyi}

The alpha-toxin gene (GenBank: Z48636) of C. novyi was selected to design the primers of $C$. novyi by exploring the GenBank database of NCBI. The specificity of primers was positively tested by using the BLAST tool of NCBI (http://www.ncbi. nlm.nih.gov/blast) (Table 1).

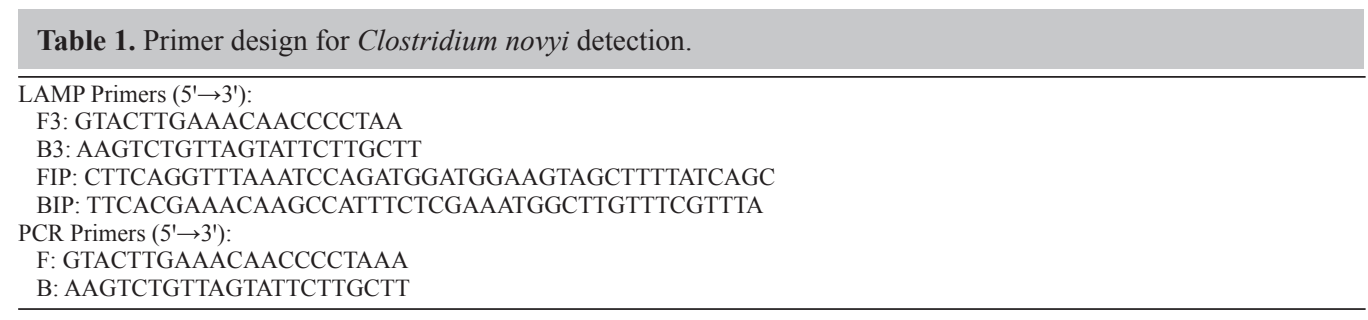

\section{Optimization of the cyclic voltammetry measurement}

The DNA was amplified through the LAMP reaction and the DNA amplification products were combined with positive dyes (such as methylene blue), leading to a reduction of free dye and could be real-time monitored by using the cyclic voltammetry methods (Figure 2, part A). With the passage of time, the oxidation peak current (ipA) was reduced, but in $30 \mathrm{~min}$, the ipA reduced more quickly (Figure 2, part B). Therefore, we used 30-min intervals as the main monitoring points in ipA measurements of cyclic voltammetry in subsequent tests. The reduction of the ipA/ipC of the cyclic voltammetry was proportional to the amount of DNA; thus, the copies of template DNA were quantitatively detected.

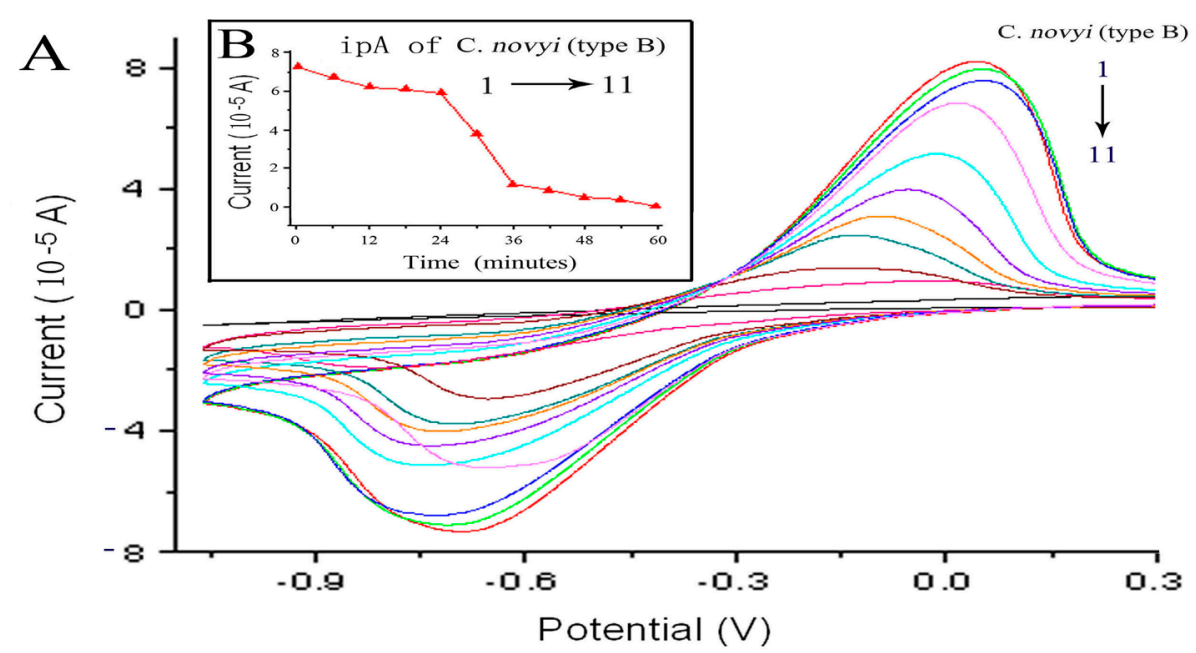

Figure 2. Optimization of cyclic voltammetry measurement. A. Cyclic voltammetry curves with the change of reaction time. B. ipA values of cyclic voltammetry with the change of reaction time. (Reaction time: from 1-11:0 to 60 every $6 \mathrm{~min}$.). Measured for DNA of $1.0 \mathrm{~mL}$ Clostridium novyi type B ( 1 x $\left.10^{5} \mathrm{CFU} / \mathrm{mL}\right)$. 


\section{Specificity analysis of the method to $C$. novyi}

Figure 3 shows that the 3 types of C. novyi (types A, B, and C) were positively detected and the 10 other kinds of bacteria were negatively detected. This suggested a high specificity of the LAMP assay for detection of C. novyi. Furthermore, the quantitative determination of $C$. novyi was more easily achieved by the cyclic voltammetry analysis.

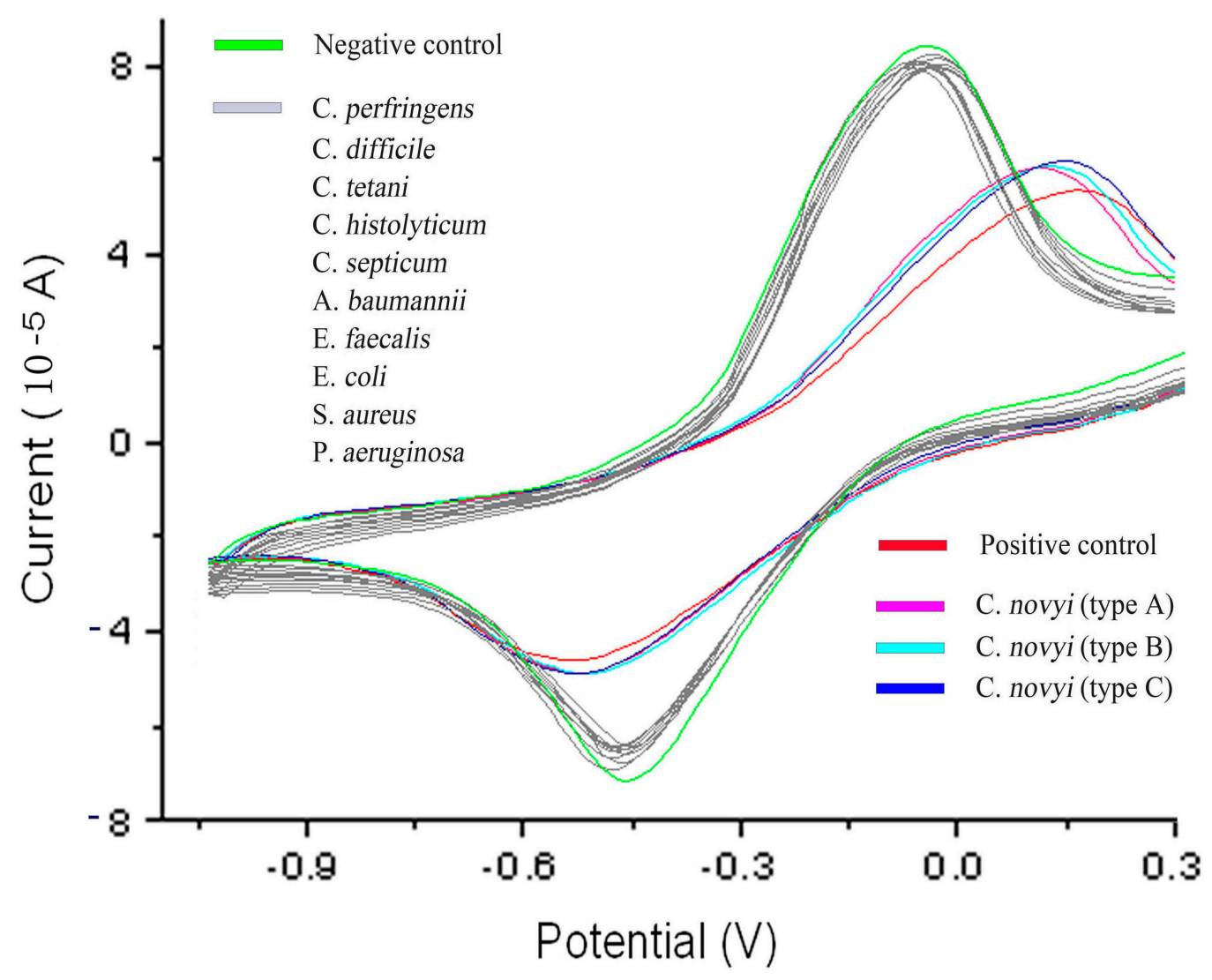

Figure 3. Specificity analysis of cyclic voltammetry measurement. Three types of Clostridium novyi and 10 kinds of other bacteria were measured for DNA in the same way of $1.0 \mathrm{~mL}$ bacteria $\left(1 \times 10^{5} \mathrm{CFU} / \mathrm{mL}\right)$.

\section{Sensitivity and regression analysis of the method}

The results of cyclic voltammetry measurement showed that the detection limit of cyclic voltammetry measurement for $C$. novyi was lowest at $1 \times 10^{2} \mathrm{CFU} / \mathrm{mL}$, indicating a high sensitivity (Figure 4, part A). A linear relationship between the C. novyi concentration and the ipA of cyclic voltammetry over a range of $1 \times 10^{0}$ to $1 \times 10^{6} \mathrm{CFU} / \mathrm{mL}$ was obtained (y $\left.=-1.3511 \mathrm{x}+8.1061, \mathrm{R}^{2}=0.9755\right)$ (Figure 4 , part B). The quantification of the C. novyi copy number in the samples could be extrapolated by the cyclic voltammetry measurement. 


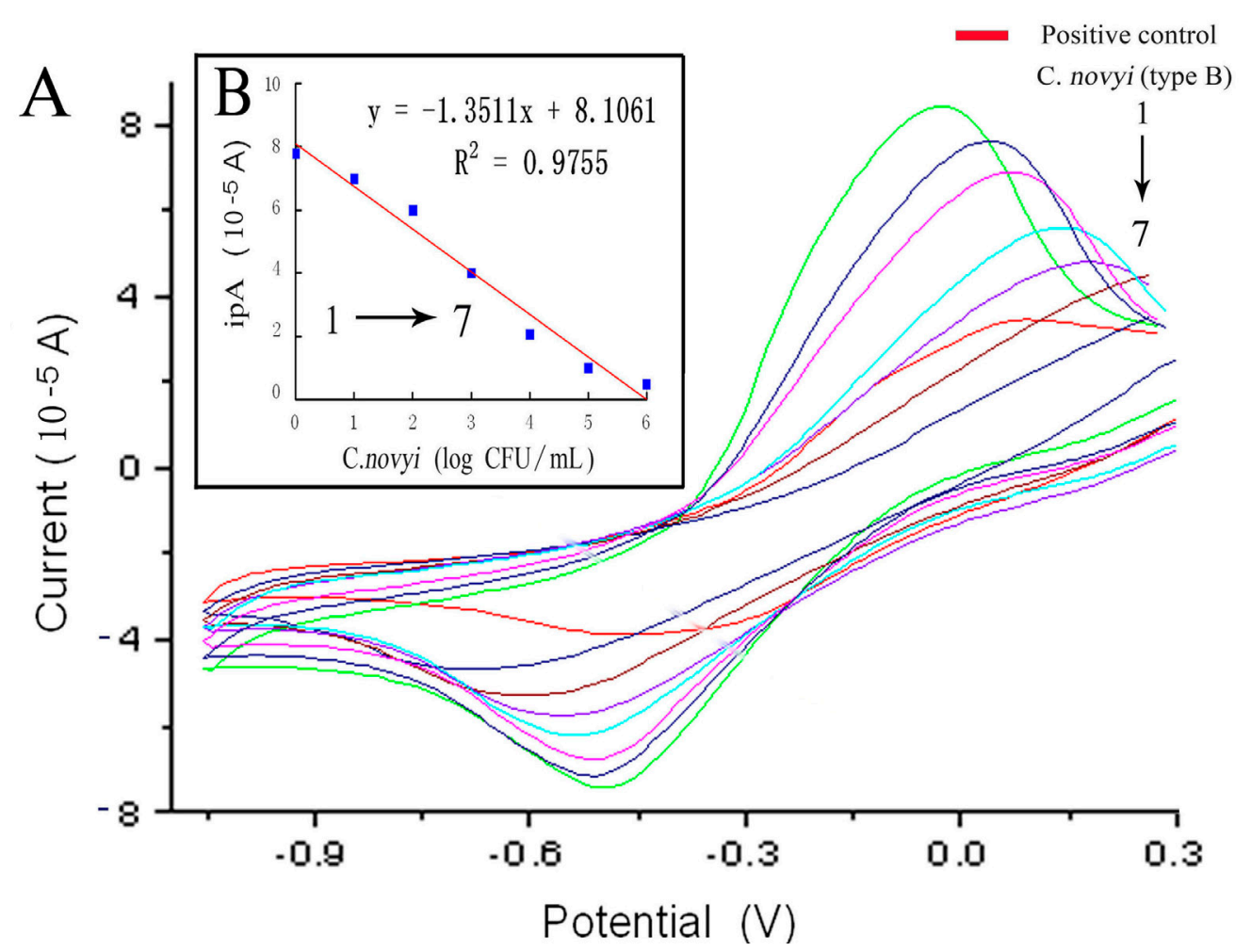

Figure 4. Sensitivity of cyclic voltammetry measurement for Clostridium novyi type B. A serial of concentrations (1-7: $1 \times 10^{2}$ to $1 \times 10^{6} \mathrm{CFU} / \mathrm{mL}$ ) were measured for DNA in the same way of $1.0 \mathrm{~mL}$ C. novyi type B.

\section{Comparative analysis with PCR}

The results of comparison between the cyclic voltammetry measurement and PCR identification (Table 2) suggested that there were no significant differences between the cyclic voltammetry measurement and anaerobic culture identification $(\mathrm{P}>0.05)$. The cyclic voltammetry measurement had high accuracy (96.5\%), sensitivity (96.0\%), and specificity $(97.0 \%)$ compared to the standard anaerobic cultivation method.

\begin{tabular}{|c|c|c|c|c|c|c|c|}
\hline \multirow[t]{2}{*}{ Cyclic voltammetry } & \multicolumn{2}{|c|}{ PCR } & \multicolumn{2}{|c|}{$\chi^{2}$ test } & \multirow[t]{2}{*}{ Accuracy } & \multirow[t]{2}{*}{ Sensitivity } & \multirow[t]{2}{*}{ Specificity } \\
\hline & + & - & $\chi^{2}$ & $P$ & & & \\
\hline $\begin{array}{l}+ \\
-\end{array}$ & $\begin{array}{c}96 \\
3\end{array}$ & $\begin{array}{c}4 \\
97\end{array}$ & 0.1429 & $0.7055^{*}$ & $96.5 \%$ & $96.0 \%$ & $97.0 \%$ \\
\hline
\end{tabular}

*There is no statistical difference between the two methods $(\mathrm{P}>0.05)$.

\section{DISCUSSION}

The Black disease is an acute, highly fatal disease of sheep and cattle, caused by $C$. novyi type B (Bagadi and Sewell, 1973). It may be present on skin surfaces and is a potential 
source of wound infections (Plomp et al., 2007). The lethal and necrotizing toxins (primarily $\alpha$ toxin) damage hepatic parenchyma, thereby permitting the bacteria to multiply and produce a lethal amount of toxin (Guttenberg et al., 2011). Most of characteristic lesions are the grayish yellow, necrotic foci in the liver that often follow the migratory tracks of the young flukes. Usually, there is extensive rupture of the capillaries in the subcutaneous tissue, which causes the adjacent skin to turn black, leading to so-called Black disease. The onset of disease and death is usually so rapid that treatment is rarely successful or worthwhile. Vaccination effectively prevents Black disease, but vaccination for Black disease will not prevent death or loss of production due to liver fluke infestation. Early diagnosis and prompt treatment are very important in preventing sheep and cattle from Black disease.

C. novyi is an obligate anaerobic bacterium of the Clostridia class. It is pathogenic, causing a wide variety of diseases in humans and animals. It comes in 3 types, A, B, and a non-pathogenic type, $\mathrm{C}$, that are distinguished by the range of toxins they produce. The existing tools for the diagnosis of Black disease include microscopy, antigen/enzyme detection, anaerobic cultivation, and molecular detection. Microscopy and antigen/enzyme tests remain the only feasible options for Black disease detection in many endemic countries. They can provide quantitative data and can identify species when used appropriately. Anaerobic cultivation and identification is currently used as the "gold standard" technique. However, anaerobic cultivation requires relatively high-standard laboratory facilities and is time-consuming, consequently leading to a delay beyond the optimal time window for treatment. The nucleic acid-based molecular methods are potentially good alternatives as they can accurately differentiate all species and detect at low levels. PCR-based diagnosis recently helped to identify samples that had been misdiagnosed using microscopy. The LAMP method is relatively simple and can be improved for better use in endemic countries. Compared with traditional PCR, LAMP is simpler, faster, and does not require expensive equipment. In recent years, LAMP technology has made progress in detections of viruses, bacteria, parasites, food safety, and animal embryo sex identifications. It had become a used in routine detections of the pathogenic microorganisms.

In this paper, we proposed an electrochemical detection method, cyclic voltammetry measurement, for the amplification and detection of DNA. First, the C. novyi Black disease toxin gene from NCBI (GenBank: Z48636) was selected as the target gene, and the primers were designed to target the relatively conserved regions of the gene identified through sequence alignments. Then, DNA extracted from specimens was amplified through the LAMP reaction. Then, the products were combined with the positive dye Methylene blue, leading to a reduction in the oxidation peak current (ipA) and a reduction in the peak current (ipC) of the cyclic voltammetry. The changes of $\mathrm{ipA} / \mathrm{ipC}$ were real-time measured by a specially designed electrode. With the passage of time, the oxidation peak current (ipA) and reduction peak current (ipC) were reduced, but in $30 \mathrm{~min}$, the ipA reduced more quickly; therefore, $30 \mathrm{~min}$ was taken as the main monitoring point in ipA measurements of cyclic voltammetry in the following tests. The results suggested that it had good specificity in detecting $C$. novyi and could accurately measure 3 types of $C$. novyi. Because of the lack understanding of gene sequence of $C$. novyi, we cannot currently distinguish the 3 types by the cyclic voltammetry measurement; however, this does not affect the diagnosis of Black disease. Combined with microscopy and antigen or enzyme tests, we could ultimately identify C. novyi. Furthermore, the results displayed that this electrochemical detection of $C$. novyi could be completed within 1 to $2 \mathrm{~h}$ with bacterial concentrations as low as $10^{2} \mathrm{CFU} / \mathrm{mL}$. The results of comparisons between the cyclic voltammetry measurement and PCR identification suggested that there were no signifi- 
cant differences between the 2 methods $(\mathrm{P}>0.05)$. The cyclic voltammetry measurement had high accuracy $(96.5 \%)$, sensitivity $(96.0 \%)$, and specificity $(97.0 \%)$ compared to the standard PCR method.

In conclusion, the cyclic voltammetry measurement was shown to be a simple and fast method for C. novyi diagnosis, with high sensitivity and high specificity, and therefore has great potential to be a usable molecular tool for the fast diagnosis of Black disease.

\section{ACKNOWLEDGMENTS}

Research supported by the National Natural Science Foundation of China (NSFC, \#81371898) and the Chongqing Science and Technology Commission (CSTC, \#2011AB5035). We appreciate the valuable comments from other members of our laboratories.

\section{REFERENCES}

Abdul-Ghani R, Al-Mekhlafi AM and Karanis P (2012). Loop-mediated isothermal amplification (LAMP) for malarial parasites of humans: would it come to clinical reality as a point-of-care test? Acta Trop. 122: 233-240.

An Y, Reimers K, Allmeling C, Liu J, et al. (2012). Validation of differential gene expression in muscle engineered from rat groin adipose tissue by quantitative real-time PCR. Biochem. Biophys. Res. Commun. 421: 736-742.

Aronson AI and Fitz-James P (1976). Structure and morphogenesis of the bacterial spore coat. Bacteriol. Rev. 40: 360-402.

Badenoch PR, Mills RA, Woolley MW and Wetherall BL (2007). Clostridium novyi keratitis. Br. J. Ophthalmol. $91: 691$.

Bagadi HO and Sewell MM (1973). Experimental studies on infectious necrotic hepatitis (Black Disease) of sheep. Res Vet. Sci. 15: 53-61.

Belokopytov BF, Ryzhmanova I, Laurinavichius KS and Shcherbakova VA (2012). Prolonged cultivation of an anaerobic bacterial community producing hydrogen. Prikl Biokhim. Mikrobiol. 48: 218-225.

Brazier JS, Duerden BI, Hall V, Salmon JE, et al. (2002). Isolation and identification of Clostridium spp. from infections associated with the injection of drugs: experiences of a microbiological investigation team. J. Med. Microbiol. 51: 985-989.

Chang SC, Rodrigues NP, Zurgil N, Henderson JR, et al. (2005). Simultaneous intra- and extracellular superoxide monitoring using an integrated optical and electrochemical sensor system. Biochem. Biophys. Res. Commun. 327: 979-984.

Cooney CG, Sipes D, Thakore N, Holmberg R, et al. (2012). A plastic, disposable microfluidic flow cell for coupled onchip PCR and microarray detection of infectious agents. Biomed. Microdevices 14: 45-53.

Eeckhaut V, Boyen F, Pasmans F, Uzal FA, et al. (2012). Clostridium novyi type B as a causative agent of bovine meat spoilage. Anaerobe 18: 286-288.

Guttenberg G, Papatheodorou P, Genisyuerek S, Lu W, et al. (2011). Inositol hexakisphosphate-dependent processing of Clostridium sordellii lethal toxin and Clostridium novyi $\alpha$-toxin. J. Biol. Chem. 286: 14779-14786.

Hatheway CL (1990). Toxigenic clostridia. Clin. Microbiol. Rev. 3: 66-98.

Nogami H, Tsutsumi H, Komuro T and Mukoyama R (2008). Rapid and simple sex determination method from dental pulp by loop-mediated isothermal amplification. Forensic Sci. Int. Genet. 2: 349-353.

Notomi T, Okayama H, Masubuchi H, Yonekawa T, et al. (2000). Loop-mediated isothermal amplification of DNA. Nucleic Acids Res. 28: E63.

Paris DH, Blacksell SD, Nawtaisong P, Jenjaroen K, et al. (2011). Diagnostic accuracy of a loop-mediated isothermal PCR assay for detection of Orientia tsutsugamushi during acute Scrub Typhus infection. PLoS Negl. Trop. Dis. 5: e1307.

Parsonson I (2007). Epidemic catarrh of sheep: the possible role of black disease. Aust. Vet. J. 85: 78-83.

Plomp M, McCaffery JM, Cheong I, Huang X, et al. (2007). Spore coat architecture of Clostridium novyi NT spores. J. Bacteriol. 189: 6457-6468.

Shi Q, Liu GH, Yan HQ and Zhang HL (2012). Black disease (Terpios hoshinota): a probable cause for the rapid coral mortality at the northern reef of Yongxing Island in the South China Sea. Ambio 41: 446-455.

Sowmya N, Thakur MS and Manonmani HK (2012). Rapid and simple DNA extraction method for the detection of enterotoxigenic Staphylococcus aureus directly from food samples: comparison of PCR and LAMP methods. J. Appl. Microbiol. 113: 106-113. 
Traverso M, Malnati M, Minetti C, Regis S, et al. (2006). Multiplex real-time PCR for detection of deletions and duplications in dystrophin gene. Biochem. Biophys. Res. Commun. 339: 145-150.

Wang X, Zhu JP, Zhang Q, Xu ZG, et al. (2012). Detection of enterovirus 71 using reverse transcription loop-mediated isothermal amplification (RT-LAMP). J. Virol. Methods 179: 330-334.

Xu YJ, Tian XH, Zhang XZ, Gong XH, et al. (2012). Simultaneous determination of malachite green, crystal violet, methylene blue and the metabolite residues in aquatic products by ultra-performance liquid chromatography with electrospray ionization tandem mass spectrometry. J. Chromatogr. Sci. 50: 591-597.

Yue M, Schmieder R, Edwards RA, Rankin SC, et al. (2012). Microfluidic PCR combined with pyrosequencing for identification of allelic variants with phenotypic associations among targeted Salmonella genes. Appl. Environ. Microbiol. 78: 7480-7482.

Zhang YQ, Shan XX, Shi L, Lu X, et al. (2012). Development of a fimY-based loop-mediated isothermal amplification assay for detection of Salmonella in food. Food Res. Int. 45: 1011-1015. 